\title{
Commentary: Is surgical ablation concomitant with coronary artery bypass grafting cost effective? No answers, just questions
}

\author{
Vijay S. Patel, MD, and Richard Lee, MD, MBA
}

\author{
From the Division of Cardiothoracic Surgery, Department of Surgery, Medical College of Georgia, Augusta Uni- \\ versity, Augusta, Ga. \\ Disclosures: Authors have nothing to disclose with regard to commercial support. \\ Received for publication Aug 1, 2019; accepted for publication Aug 1, 2019; available ahead of print Sept 5, 2019 \\ Address for reprints: Richard Lee, MD, MBA, Division of Cardiothoracic Surgery, Department of Surgery, Med- \\ ical College of Georgia, Augusta University, 1120 15th St, BA 4300, Augusta, GA 30912 (E-mail: ricklee@ \\ augusta.edu). \\ J Thorac Cardiovasc Surg 2020;160:689-90 \\ $0022-5223 / \$ 36.00$ \\ Copyright (C) 2019 Published by Elsevier Inc. on behalf of The American Association for Thoracic Surgery \\ https://doi.org/10.1016/j.jtcvs.2019.08.010
}

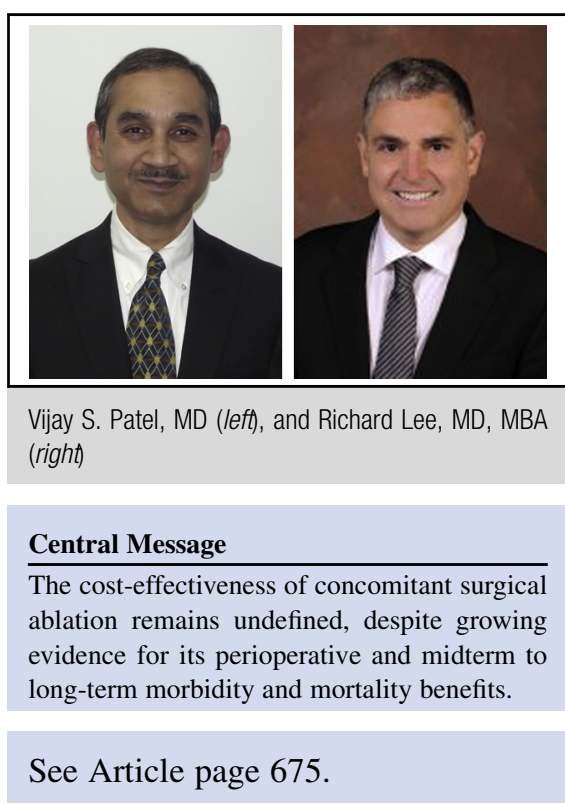

long term, with improvement in risk-adjusted late mortality benefit for the CSA group.

At first glance, the analysis and findings of Rankin and colleagues ${ }^{9}$ appear to be encouraging, lending incremental support in favor of CSA intervention for a presumed reduction in the future cost of medical care and improved mortality. Nevertheless, closer scrutiny of their report highlights significant limitations.

It must be emphasized that use of the Medicare administrative database inherently lacks exhaustive clinically relevant data with desired specificity, and important information valuable to this investigation cannot reliably be assured in the absence of explicit details for all future readmissions, outpatient services, and interventions. These deficiencies can significantly underestimate the financial analysis. Moreover, since there was a positive impact on survival, presumably there should be more readmissions among the sicker AF-treated survivors than among the nontreated deceased. Although clearly an advantage for the survivors, CSA treatment may and should be relatively more expensive. This type of analysis is critical in assessing the cost to benefit ratio of any intervention.

The inherent selection bias makes it nearly impossible to interpret the results. Only $17 \%$ of the patients received CSA. The untreated group had significantly higher comorbidities and predispositions to readmission, such as 
congestive heart failure, renal failure, and lung disease. This likely influenced negative long-term outcomes for the untreated high-risk group relative to the low-risk CSA group. Moreover, the "healthier" treated patients should theoretically be much less expensive if there were a benefit to therapy. The fact that the price is the same suggests that it may be relatively more expensive (if the patients were appropriately adjusted).

Further, the article is also deficient in the tabulation of several critical factors, including perioperative morbidities, details of the CSA procedures, successful attainment of sinus rhythm, the specific cause of mortality, and improvement in the quality of life measures. In addition, it fails to compare the entire AF group and a no preoperative $\mathrm{AF}$ CABG group, which would provide invaluable insight into the relative impact of the AF on outcomes-if any.

This article by Rankin and colleagues ${ }^{9}$ provides an important early step on the path to understanding the effects of treating $\mathrm{AF}$ on long-term patient outcomes. Unfortunately, after we read it, we find no answers, merely more questions.

\section{References}

1. Saxena A, Virk SA, Bowman S, Chan L, Jeremy R, Bannon PG. Preoperative atrial fibrillation portends poor outcomes after coronary artery bypass graft surgery: a systematic review and meta-analysis. J Thorac Cardiovasc Surg. 2018;155:1524-33.e2.

2. Malaisrie SC, McCarthy PM, Kruse J, Matsouaka R, Andrei AC, GrauSepulveda MV, et al. Burden of preoperative atrial fibrillation in patients undergoing coronary artery bypass grafting. J Thorac Cardiovasc Surg. 2018;155: 2358-67.e1.

3. Lee R, McCarthy PM, Wang EC, Vaduganathan M, Kruse J, Malaisrie SC, et al. Midterm survival in patients treated for atrial fibrillation: a propensity-matched comparison to patients without a history of atrial fibrillation. $J$ Thorac Cardiovasc Surg. 2012;143:1341-51.

4. Badhwar V, Rankin JS, Damiano RJ Jr, Gillinov AM, Bakaeen FG, Edgerton JR, et al. The Society of Thoracic Surgeons 2017 clinical practice guidelines for the surgical treatment of atrial fibrillation. Ann Thorac Surg. 2017;103:329-41.

5. Ad N, Damiano RJ Jr, Badhwar V, Calkins H, La Meir M, Nitta T, et al. Expert consensus guidelines: examining surgical ablation for atrial fibrillation. J Thorac Cardiovasc Surg. 2017;153:1330-54.e1.

6. Badhwar V, Rankin S, Ad N, Grau-Sepulveda M, Damiano RJ, Gillinov AM, et al. Surgical ablation of atrial fibrillation in the United States: trends and propensity matched outcomes. Ann Thorac Surg. 2017; 104:493-500

7. McCarthy PM. We don't know what we need to know about atrial fibrillation. J Thorac Cardiovasc Surg. 2018;155:1522-3.

8. Nashef SAM, Abu-Omar Y. Concomitant atrial fibrillation: worth the effort? Eur J Cardiothorac Surg. 2018;53:114-8.

9. Rankin JS, Lerner DJ, Braid-Forbes MJ, McCrea ML, Badhwar V. Surgical ablation of atrial fibrillation concomitant to coronary-artery bypass grafting provides cost-effective mortality reduction. J Thorac Cardiovasc Surg. 2020; 160:675-86.e13.

10. Rankin JS, Lerner DJ, Braid-Forbes MJ, Ferguson MA, Badhwar V. One-year mortality and costs associated with surgical ablation for atrial fibrillation concomitant to coronary artery bypass grafting. Eur J Cardiothorac Surg. 2017;52:471-7. 